\title{
Hibridación y diferenciación discursiva entre kleinismo y lacanismo (Uruguay, 1955-1982)*1
} \section{between Kleinism and Lacanism (Uruguay, 1955-1982)}

Discursive hybridization and differentiation

Gonzalo Grau-Pérez*2

Guillermo Milán*3

En Uruguay, las ideas lacanianas arriban en la década de 1960, en un contexto de hegemonía kleiniana. En este trabajo se describen los procesos y fenómenos discursivos a partir de los cuales el lacanismo se relaciona y articula con el kleinismo de la época.

Para llevar adelante esta investigación, se construyó un corpus de datos discursivos a partir de casos clínicos y artículos teórico-doctrinales publicados en la Revista Uruguaya de Psicoanálisis entre 1955 y 1982.

${ }^{* 1}$ Este texto corresponde a una versión modificada de un apartado perteneciente a la tesis de Maestría "Klein con Lacan: un estudio discursivo de la recepción de las ideas lacanianas en Uruguay (1955-1982)", autoría de Gonzalo Grau-Pérez y dirección de tesis de Guillermo Milán. La tesis, defendida en 2018, puede ser recuperada de www.colibri.udelar.edu.uy (repositorio institucional de la Universidad de la República).

Asimismo, esta investigación se enmarca en el trabajo del grupo Formación de la clínica psicoanalítica en el Uruguay (FCPU) de la Facultad de Psicología (Udelar), y fue financiada por la Agencia Nacional de Investigación e Innovación (ANII) en el marco de una beca de posgrado (Código: POS_NAC_2015_1_110134).

*2,3 Universidad de la República (Montevideo, Uruguay). 
Los materiales discursivos que constituyen el corpus muestran diversos modos de entrecruzamiento, hibridación y diferenciación entre teorías. A partir de estos fenómenos, se discuten algunos aspectos del proceso de recepción de Lacan en Uruguay.

Palabras clave: Kleinismo, lacanismo, Uruguay, análisis del discurso.

\section{Introducción}

Tal como sucedió en otros países de la región, en Uruguay el psicoanálisis se desarrolló, desde su institucionalización en la década de 1950, y hasta la década de 1970, con una orientación kleiniana dominante. Es a partir de la década de 1970 que el psicoanálisis del Río de la Plata se desplaza de este escenario kleiniano a una situación de "pluralismo abierto a múltiples enfoques" (Bernardi, 2010, p. 90). Precisamente, la relevancia de estudiar esta época estaría dada por el hecho de que constituiría un punto de inflexión en la historia del psicoanálisis uruguayo. Entre estos "nuevos enfoques" que comenzaron a desarrollarse en aquel momento, habría tenido un lugar destacado la perspectiva de Jacques Lacan (cf. Bernardi, 2002, p. 266); por ello, en este trabajo nos proponemos estudiar los procesos y fenómenos discursivos que caracterizaron la recepción de las ideas lacanianas en este contexto de hegemonía kleiniana. Se trataría de un proceso histórico-discursivo original de la región: ni en Europa ni en Estados Unidos las ideas lacanianas habrían desembarcado en un ambiente de preeminencia kleiniana.

Como puede ser observado en la bibliografía psicoanalítica de la época - década de 1970 y principios de la década de 1980 se produjo, en Uruguay, un aumento significativo de referencias y alusiones a Lacan, fenómeno que es concomitante al surgimiento de grupos de estudio sobre sus textos, la visita de algunos discípulos directos, ${ }^{1}$ e, igualmente, la fundación en 1982 de la Escuela Freudiana

${ }^{1}$ En el año 1972 Octave y Maud Mannoni, y luego Serge Leclaire, visitan Uruguay y Argentina. En Uruguay, realizan una serie de seminarios y conferencias en la Asociación Psicoanalítica del Uruguay. En 1975 Leclaire vuelve a visitar Uruguay. 
de Montevideo (EFM), primera institución específicamente lacaniana en Uruguay. Las diferentes controversias, encrucijadas, compromisos, conversiones, quedaron inscriptas y materializadas, de diversas formas, en la escritura de los psicoanalistas, en los trabajos teórico-doctrinales y casos clínicos de la época.

Kleinismo y lacanismo suponen diferencias teóricas importantes, que conducen a prácticas clínicas divergentes; se trataría de paradigmas verdaderamente inconmensurables (cf. Allouch, 1993/2006, 1994; Baños Orellana, 1995; Bernardi, 1989; Birman, 2014). ¿Cómo se da, en un contexto kleiniano, la recepción de ideas lacanianas? ¿Qué fenómenos discursivos caracterizan este proceso? ¿Cuáles divergencias y qué "soluciones de compromiso" se establecieron entre kleinismo y lacanismo en el psicoanálisis uruguayo de la época? Para abordar este problema nos apoyamos en la tradición de estudios discursivos iniciada en Francia por Michel Pêcheux, e integramos, al mismo tiempo, algunos aportes del método arqueológico de Foucault, que mantiene una afinidad epistemológica con la perspectiva de Pêcheux.

Así, hemos caracterizado operativamente al kleinismo y al lacanismo como formaciones discursivas (cf. Foucault, 1969/2002; Pêcheux, 1975/ 2016), y, a partir de esto, hemos identificado dos modos fundamentales de relación entre ambas, dos fenómenos discursivos que hemos llamado hibridación y diferenciación. A grandes rasgos, entendemos por hibridación un fenómeno discursivo que, a primera vista, se muestra como una "mezcla indiscernible" de elementos de diferentes formaciones discursivas, sin marcas - o con marcas muy débiles - que introduzcan distancias, divergencias, diferencias, entre ellos. Por otra parte, concebimos la diferenciación como un proceso por el cual dos formaciones discursivas son presentadas o reconocidas como diferentes; entre los elementos de ambas, hay marcas muy definidas que establecen distancias o demarcaciones. Tanto en la hibridación como en la diferenciación habría una disimulaciónopacificación de las relaciones de hegemonía o dominio entre las formaciones discursivas en juego, aquello que Pêcheux (1975/2016, p. 144) denomina "desigualdad-contradicción-subordinación".

Estos fenómenos discursivos se podrían representar como constituyendo un continuum entre el mayor nivel de hibridación y el mayor nivel de diferenciación; un gradiente que iría del primero al segundo, atravesando, en determinado momento, el umbral a partir del cual se pasaría de la hibridación a la diferenciación. Esta imaginarización en términos de continuum supone una primera representación, una primera tentativa de dar inteligibilidad a fenómenos y procesos que no se desarrollan de forma lineal o uniforme. 
Hemos trabajado estos fenómenos discursivos como si fueran,

Hemos trabajado estos fenómenos discursivos como si fueran, hasta cierto punto, independientes de la cronología, de los autores, de los artículos, etc. De esta forma, siguiendo un principio de método propuesto por Foucault (1969/2002), intentamos aislar regularidades del discurso sin considerar las continuidades de sentido creadas en torno a unidades tales como autor, obra, artículo o época. Los fenómenos discusivos que hemos identificado - con su respectiva variedad de formas - se superponen, divergen y se difractan sin reflejar la linealidad o el desarrollo del tiempo cronológico, la unidad de la autoría, e incluso, la unidad o coherencia de un mismo texto.

El corpus de datos utilizado para llevar adelante este análisis fue construido a parir de la Revista Uruguaya de Psicoanálisis (RUP), órgano oficial de la Asociación Psicoanalítica del Uruguay (APU) ${ }^{2}$ incluye casos clínicos y artículos teórico-doctrinales. Elegimos como recorte cronológico el período que va de 1955 a 1982: en 1955, con la fundación de la APU, comienza a consolidase la institucionalización del psicoanálisis; y en 1982, con la fundación de la EFM, "culmina" un primer momento de institucionalización del lacanismo.

\section{Hibridación discursiva entre kleinismo y lacanismo}

En esta sección presentamos material discursivo a partir del cual nos proponemos mostrar un proceso de hibridación entre formaciones discursivas. Bajtín (1975/1989) ha llamado hibridación a "la mezcla de dos lenguajes sociales en el marco del mismo enunciado; es el encuentro en la pista de ese

${ }^{2}$ Esta elección se justifica por el hecho de que, en Uruguay, la recepción inicial de Lacan se dio en el ámbito de la APU, en la década de 1960. Esto marcaría una diferencia con lo ocurrido en Argentina, donde la recepción de Lacan se habría dado, en un primer momento, fuera de la Asociación Psicoanalítica Argentina, es decir, fuera de la International Psychoanalytical Association (cf. Balán, 1991; Bernardi, 2010; Dagfal, 2009; García, 2005; Izaguirre, 2009; Plotkin, 2003).

${ }^{3}$ Bajtín (1975/1989) distingue la hibridación intencional, como la que se da en el caso de la novela, de la no intencional, que sería: "una de las modalidades principales de la conciencia histórica y del proceso de formación de los lenguajes. Se puede afirmar abiertamente que la lengua y los lenguajes se modifican básicamente, desde el punto 
enunciado de dos conciencias lingüísticas separadas por la época o por la diferenciación social" (p. 174). ${ }^{3}$ Asimismo, llama:

[...] construcción híbrida al enunciado que, de acuerdo con sus características gramaticales (sintácticas) y compositivas, pertenece a un solo hablante; pero en el cual, en realidad, se mezclan dos enunciados, dos maneras de hablar, dos estilos, dos "lenguas", dos perspectivas semánticas y axiológicas. Repetimos que, entre estos enunciados, estilos, "lenguas" y perspectivas, no existe ninguna frontera formal-compositiva ni sintáctica; la separación de voces y de lenguajes se desarrolla en el marco de un único todo sintáctico, frecuentemente en los límites de una proposición simple; incluso muchas veces, la misma palabra pertenece simultáneamente a dos lenguajes, tiene dos perspectivas que se cruzan en la construcción híbrida y tiene, por lo tanto, dos sentidos contradictorios, dos acentos... (pp. 121-122)

Tomamos la descripción de hibridación de Bajtín como punto de partida, para ilustrar este principio de análisis. ${ }^{4}$ Desde el punto de vista del análisis del discurso, entenderemos por hibridación aquel fenómeno que, a primera vista, se muestra en el hilo del discurso (intradiscurso) como el resultado de un proceso de yuxtaposición o "mezcla" indiscriminada, no diferenciada, de elementos provenientes de diferentes formaciones discursivas, como si se hubiese producido una supresión de sus fronteras. ${ }^{5}$ Entre estos elementos no se encuentran marcas - o cuando se las encuentra, son muy débiles - que introduzcan distancias, divergencias, diferencias, etc. Atendiendo al principio por el cual la relación entre formaciones discursivas está regulada por la ley

de vista histórico, por medio de la hibridación, de la mezcla de diversas «lenguas» que coexisten en los límites de un dialecto, de una lengua nacional, de una rama, de un grupo de ramas o de diferentes grupos, (...); y el enunciado siempre sirve de recipiente de esa mezcla" (p. 175).

${ }^{4}$ Desde la antropología también se ha hecho uso de una noción de hibridación, para dar cuenta del entrecruzamiento y la yuxtaposición de culturas (cf. García Canclini, 1990).

${ }^{5}$ Todo discurso está habitado, "parasitado", por otros discursos (Dunker, Paulon, \& Milán-Ramos, 2016, p. 124; Pêcheux,1983/1997, p. 314). Authier-Revuz (1990) llama a esta propiedad heterogeneidad constitutiva. Esta heterogeneidad puede estar constituida de diversas formas; en los casos de hibridación que presentamos aquí, la heterogeneidad queda disimulada a través de un proceso que "homogeneiza" lacanismo y kleinismo de forma que parece que se tratara de una misma formación discursiva. Bajtín (1975/1989, p. 137) ha caracterizado la hibridación como una supresión de fronteras discursivas. 


\section{HISTÓRIA DA PSICANÁLISE}

de "desigualdad-contradicción-subordinación" (Pêcheux, 1975/2016, p. 144), podemos considerar que la hibridación no es una simple mezcla caótica o anárquica, sino que hay diversos efectos de dominio discursivo. Esta relación de "desigualdad-contradicción-subordinación" quedaría, en mayor o menor medida, disimulada-opacificada. Es así que el proceso adquiere el aspecto de mezcla indiscriminada y de "borramiento" de las fronteras discursivas. En definitiva, no se trata de una hibridación "proporcionada", "equilibrada", "simétrica", sino del efecto de una "relación de fuerzas desigual" (cf. Pêcheux, 1983/1997, p. 314) donde, en este caso, el kleinismo suele ejercer una función de dominio del sentido: Lacan es leído "kleinianamente". Este efecto de "aplanamiento-rebajamiento" del discurso generado por el proceso de hibridación es correlativo del desconocimiento de las diversas formas de subordinación que, en estos casos, el lacanismo tiene en relación al kleinismo. ${ }^{6}$

En un sentido descriptivo, hemos distinguido y caracterizado diferentes formas de hibridación. En este trabajo presentamos ejemplos de una de ellas, que hemos llamado hibridación por coexistencia de términos y expresiones. ${ }^{7}$

${ }^{6}$ La hibridación discursiva también podría ser descrita como un espacio o región de "superposición de formaciones discursivas diferentes" (Dunker et al., 2016, p. 115). Los efectos de la hibridación dependerán de los compromisos, transacciones y determinaciones que se establezcan entre las formaciones discursivas en juego. Por ejemplo, Foucault (1975/2000, pp. 40-41) ha mostrado en ciertos ámbitos, como el de la pericia médico-legal, una suerte de "alianza" entre el discurso médico y el discurso judicial. Este fenómeno podría ser pensado como un proceso de hibridación discursiva, que tendría la característica, en este caso, de producir un nuevo sentido, un nuevo espacio: una región que permitiría "el funcionamiento de las nociones médicas en el campo del poder judicial y, a la inversa, las nociones jurídicas en el ámbito de competencia de la medicina" (Foucault, 1975/2000, p. 41). Las diferentes nociones de perversidad funcionarían como nociones hibridas, en tanto permitirían "coser" categorías jurídicas y médicas. Asimismo, tanto el discurso médico como el discurso judicial estarían, a su vez, subordinados a otro poder, que también podría considerarse como otro discurso, con su autonomía y reglas propias: el discurso de la normalización (Foucault, 1975/2000, p. 38). Así, sería posible encontrar formas de hibridación que producen nuevos sentidos o crean nuevas regiones de funcionamiento discursivo - como en este caso - y otras en las que esto no ocurre (cf. Milán-Ramos, 2019).

${ }^{7}$ Se pueden encontrar más ejemplos, así como otras formas de hibridación, en la versión completa de la tesis (Grau-Pérez, 2018). 
Esta forma de hibridación supone la coexistencia de términos y expresiones que refieren, por lo general, a nociones y conceptos kleinianos y lacanianos, sin que se visualice entre ellos conflicto o contradicción aparente. Véase el siguiente material discursivo:

(1) Este punto de urgencia no depende del paciente solo (aunque el analista haga los debidos esfuerzos para no sugerir y no imponer nada). Por su interpretación y la selección del material, asume la dirección del proceso [Lacan, La direction de la cure et les principes de son pouvoir]. El punto de urgencia es una fantasía inconsciente, pero una fantasía de pareja. A pesar de lo "pasivo" del analista, está involucrado en la fantasía del paciente. (Baranger, M., \& Baranger, W., 1964, p. 21)

Aquí se puede apreciar cómo se toma una idea extraída de Lacan (el analista como director del proceso-cura) y se la coloca en continuidad con nociones kleinianas clásicas ("fantasía inconsciente", "punto de urgencia"). No hay contradicción aparente, sino más bien, complementariedad. Un fenómeno similar ocurre en el siguiente fragmento:

(2) La ruptura de la simbiosis y la vivencia de un mundo intersubjetivo sólo se da por la aparición de un tercero. Corresponde a la descripción de M. Klein de la posición depresiva (...). En la medida en que la posición depresiva es la que posibilita el desarrollo de la función simbólica, también permite el desarrollo del lenguaje. (...). La aparición del lenguaje está, por lo tanto, íntimamente vinculada a angustias depresivas de pérdida, de separación de la madre. La palabra nombra al objeto, lo representa, pero no es el objeto mismo. Como ha dicho Lacan, la palabra es una presencia hecha de ausencia. (Sopena, 1969, pp. 13-14)

Nótese la coexistencia de términos y expresiones kleinianas y lacanianas: la "posición depresiva" (Klein) junto con la "función simbólica" (Lacan); "angustias depresivas de pérdida" y "separación de la madre" (Klein) conviven con la "palabra" en cuanto "presencia hecha de ausencia" (Lacan). Todo parece indicar que esta convivencia entre kleinismo y lacanismo se produce a partir de una "asimilación" de las ideas lacanianas a la teoría kleiniana, en la medida que ésta última ejercería, por así decir, una función dominante sobre aquellas: el sentido de los términos y expresiones lacanianas es fijado, estabilizado, según el sistema de relaciones que ofrece el kleinismo - en cuanto formación discursiva - . La paráfrasis de Lacan proviene de Función

${ }^{8}$ Este fragmento contiene la primera referencia a Lacan que hemos encontrado en el psicoanálisis uruguayo. 
y campo de la palabra y del lenguaje en psicoanálisis: "por la palabra que es ya una presencia hecha de ausencia, la ausencia misma viene a nombrarse" (Lacan, 1956/2002, p. 266). Sin embargo, esta afirmación de Lacan es leída a partir de la concepción kleiniana del lenguaje: "la palabra nombra al objeto, lo representa, pero no es el objeto mismo"; el lenguaje funcionaría aquí como un mero sistema de nomenclatura o de representación, de forma que existirían referentes independientes y anteriores a la palabra. Esta perspectiva se distancia mucho de la concepción del lenguaje con la que opera Lacan.

Dado que el sentido de las palabras y expresiones depende de la formación discursiva que habitan, es natural que el término lacaniano "simbólico" se asimile en este caso, como en otros, al sentido que puede $y$ debe tener en el kleinismo:" allí el "simbolismo" surge en la posición depresiva (Segal, 1964/1981, p. 79). Esto último es lo que permite leer la expresión "función simbólica" — en el contexto de la frase: "la posición depresiva es la que posibilita el desarrollo de la función simbólica" — como una expresión ambivalente, que se localizaría en un espacio de frontera ente las dos formaciones discursivas en juego. La idea de que la posición depresiva posibilita la función simbólica - o el proceso de formación de símboloses completamente solidaria con el kleinismo. Por lo tanto, sin que a nadie le llamara la atención, la expresión - tal como aparece en el contexto de la frase - podría haber sido dicha por cualquier kleiniano: "los procesos de sublimación y de formación de símbolos están estrechamente vinculados con conflictos y ansiedades de la posición depresiva, y son una consecuencia de éstos" (Segal, 1964/1981, p. 79). No habría en aquella expresión ("función simbólica"), en principio, ninguna presencia de lacanismo. Sin embargo, en el texto del cual fue extraído el fragmento se hacen múltiples referencias a Lacan, que atraviesan nudos argumentativos centrales, especialmente en lo referido a su noción de "lenguaje", "palabra" y "simbólico"; incluso en el propio fragmento se hace referencia a Lacan y a su noción de "palabra". Es por esto que, cuando se habla de la "función simbólica", de cierto modo permanece indeterminado si se hace desde una perspectiva kleiniana o lacaniana. Este efecto de frontera hace de ella una "expresión indecidible", de forma tal que es imposible determinar por cuál de las dos formaciones discursivas ha sido producida (Pêcheux, 1983/1997, p. 314); se trataría de una suerte de "solución de compromiso" entre kleinismo y lacanismo. Aunque

${ }^{9}$ Recuérdese que las formaciones discursivas determinan lo que puede y debe ser dicho (Foucault, 1969/2002, p. 63; Pêcheux, 1975/2016, p. 142). 
sería un compromiso desigual, puesto que una formación discursiva quedaría subordinada a la otra. Un último ejemplo, esta vez de un caso clínico:

¿Y el escenario? Ya lo he adelantado. Yo-espacio de la sesión soy la madrecuerpo; dentro de la cual ella sueña y se diferencia. Inspirándome en Lacan, puedo decir también que soy el otro, frente a quien, y con quien, Griselda rompe con su ficción narcisista de ser un sujeto, de disponer de un sujeto, cuando en verdad no lo es, cuando no dispone de sí misma. (Plá, 1970, p. 396)

A continuación de una lectura propiamente kleiniana ("Yo-espacio de la sesión soy la madre-cuerpo") se instaura una fisura en la cadena discursiva; la secuencia: "inspirándome en Lacan, puedo decir también..." daría cuenta de una forma de heterogeneidad mostrada, de connotación autonímica (cf. Authier-Revuz, 1984/1990, p. 30), donde el discurso pone explícitamente una alteridad en relación a sí mismo, alteridad que en este caso sería "Lacan". Se trata de lo que Authier-Revuz (1992/1998, p. 136) denomina modalización autonímica en discurso segundo, cuya estructura sería: "como diría X...", "para hablar de modo X...", "para retomar una expresión de X...", etc. La expresión "inspirándome en..." muestra cómo "Lacan" es colocado en un espacio exterior a la posición enunciativa desde la cual se habla ("inspirándome en $X$, puedo decir $Y$ "). Ahora bien, esta fisura discursiva quedaría suturada a partir de una operación de traducción teórica que restablecería la continuidad y encubriría cualquier forma de inconmensurabilidad: desde Klein: "Yo-espacio de la sesión soy la madrecuerpo; dentro de la cual ella sueña y se diferencia", mientras que desde Lacan: "puedo decir también que soy el otro, frente a quien, y con quien, Griselda rompe con su ficción narcisista de ser un sujeto". La expresión "puedo decir también" parece mostrar — por la vía del adverbio de inclusión (aditivo) "también" - que habría una suerte de equivalencia; se puede decir de una forma o de otra; "Klein" y "Lacan" no serían aquí más que dos formas diferentes de decir lo mismo. Por eso hemos caracterizado este fragmento, al igual que los otros, como un caso de hibridación, en la medida que habría una operación que invisibiliza las fronteras entre formaciones discursivas y las relaciones de "desigualdad-contradicción-subordinación".

En todos estos materiales discursivos, las referencias, menciones o alusiones a Lacan — o a nociones, conceptos y expresiones lacanianas - no entran en conflicto con las ideas kleinianas; más aún, parecen complementarse con ellas, como si Lacan "ratificara" a Klein e, inversamente, Klein "confirmara" a Lacan. Sin embargo, previamente habíamos afirmado que kleinismo y lacanismo serían inconmensurables; ¿cómo podría ser 
posible entonces esta coexistencia sin contradicción? Ese es precisamente el efecto discursivo que queremos analizar. Si se presta atención, la ausencia de conflicto o contradicción es solo aparente: las nociones lacanianas son "asimiladas" al kleinismo, es decir, son leídas bajo una matriz de sentido kleiniana. En términos discursivos, se podría decir que elementos provenientes de una formación discursiva se encuentran subordinados a otra formación discursiva. Recuérdese que "la formación discursiva es el lugar de la constitución del sentido" (Pêcheux, 1975/2016, p. 144), y que su relación con otras formaciones discursivas estaría regulada por un principio de "desigualdad-contradicción-subordinación".

\section{Diferenciación discursiva entre kleinismo y lacanismo}

En esta sección presentamos material discursivo a partir del cual nos proponemos mostrar operaciones de diferenciación entre formaciones discursivas. Entenderemos por diferenciación aquel fenómeno que, a primera vista, se muestra como un proceso por el cual dos formaciones discursivas son reconocidas como diferentes, representándose fronteras o límites entre ellas; si en una secuencia determinada coexisten elementos de ambas, estos son presentados con marcas muy definidas que introducen distancias, divergencias, demarcaciones. Se trataría de un proceso inverso a la hibridación.

Así, el kleinismo y el lacanismo son representados como teorías diferentes, con cierto grado de autonomía e independencia. En estos casos, pueden representarse diversos tipos de frontera discursiva: desde una frontera absolutamente "permeable", "flexible", que permite una relación de complicidad, compatibilidad, continuidad, hasta una frontera, digamos así, "infranqueable", de imposible articulación e inconmensurabilidad radical. En función de cómo sean representadas las fronteras discursivas se pueden producir diferentes efectos de disimulación, opacificación, desconocimiento, etc.

Tanto en la hibridación como en la diferenciación se pone en juego la heterogeneidad constitutiva del discurso, pero las formas de tramitar esa heterogeneidad son diferentes. En un caso predomina cierto ocultamiento o disimulación de la heterogeneidad, y en el otro prevalece un intento de control o monitoreo de esa heterogeneidad a partir de la representación de fronteras, límites, diferencias, etc. Con fines puramente descriptivos, hemos distinguido varias formas de diferenciación. En este trabajo presentamos ejemplos de

${ }^{10}$ Se pueden encontrar más ejemplos, así como otras formas de diferenciación, en la versión completa de la tesis (Grau-Pérez, 2018). 
dos de ellas, que hemos llamado diferenciación a partir de una denegación y diferenciación por disyunción exclusiva. ${ }^{10}$

\section{Diferenciación a partir de una denegación}

En esta forma de diferenciación, se representa una frontera entre las formaciones discursivas a partir de una operación de denegación que establece una oposición entre ambas. Le llamamos denegación - y no negación - porque no se trata simplemente de una negación en el sentido lógico o gramatical del término, sino de una operación por la cual se rechaza algo que se afirma en Otro lugar, en otro acto o instancia enunciativa, algo ya dicho, "situado antes, en otra parte, independientemente" (Pêcheux, 1975/2016, p. 139). ${ }^{11}$ Está en juego aquí la noción de preconstruido (Pêcheux, 1975/2016), aunque no de la forma habitual que aparece en los ejemplos de Pêcheux. Véase el siguiente material discursivo:

${ }^{11}$ Freud (1925/1976) ya había percibido cierta dimensión de este fenómeno: “[Un paciente dice] 'Usted pregunta quién puede ser la persona del sueño. Mi madre no es'. Nosotros rectificamos: entonces es su madre. Nos tomamos la libertad, para interpretar, de prescindir de la negación y extraer el contenido puro de la ocurrencia. Es como si el paciente hubiera dicho en realidad: 'Con respecto a esa persona se me ocurrió, es cierto, que era mi madre; pero no tengo ninguna gana de considerar esa ocurrencia"” (p. 253). Lo esencial no estaría tanto en omitir, rápidamente y de forma automática, el "no", sino en percibir que si el paciente necesita aclarar que no es su madre, es porque en algún lugar, en Otro lugar — antes e independientemente — , se afirma que es su madre. Si se requiere la denegación es porque en otro acto o instancia enunciativa aquello se afirma. ¿En cuál? ¿en dónde? En aquel lugar en el que se dice "con respecto a esa persona se me ocurrió, es cierto, que era mi madre". Repárese en la expresión "es cierto"; implica que se le responde a alguien, precisamente a quien realiza la afirmación en primer lugar; aquí se podría suponer que el paciente no desconocía la teorización freudiana del Edipo. Pêcheux (1975/2016, p. 147) ha señalado que en la "denegación freudiana" (Verneinung) se da el fenómeno de irrupción, en el hilo del discurso, de un pensamiento que viene de Otro lugar, de lo ya dicho en otra parte. Asimismo, también ha sido señalado de forma reiterada que "con la negación externa se refuta muy a menudo un contenido proposicional relacionado con el discurso previo, de manera que la información rechazada se interpreta como supuesta, verosímil o esperable" (Real Academia Española \& Asociación de Academias de la Lengua Española, 2009, p. 3639). 


\section{HISTÓRIA DA PSICANÁLISE}

(4) Un paciente en estado de gran angustia, empezó a rezar el Padrenuestro en su lengua materna. Al pronunciar: "Our Father [...] give us this day our daily bread [pan]", le salió breast [pecho]. Este pecho no es el de la psicología kleiniana. El lapsus deja descifrar el discurso del Otro... (Koolhaas, 1972, p. 268)

La afirmación "este pecho no es el de la psicología kleiniana" nos empuja a la pregunta: ¿por qué es necesaria tal aclaración? Veamos la función de este enunciado: hay una operación por la cual se fija explícitamente un sentido (cf. Authier-Revuz, 1992/1998, p. 31). ${ }^{12}$ Authier-Revuz muestra que, en este tipo de operación, el enunciador se "esfuerza" por suprimir un sentido que no es abolido por el contexto enunciativo (p. 30). En nuestro caso, la operación no recae sobre un elemento del decir del propio enunciador, sino sobre el lapsus de un paciente que ha sido trascripto en el texto. Por esta razón, en sentido estricto, no sería un caso de modalización autonímica, como lo son los ejemplos que describe Authier-Revuz. De cualquier forma, se fija un sentido descartando otro que se presenta como inoportuno y con el cual el lector se podría "confundir". Si es necesaria la aclaración, es porque el término "pecho" que surge del lapsus es susceptible de leerse en el "sentido kleiniano".

El material discursivo en cuestión corresponde a un texto de Gilberto Koolhaas, uno de los fundadores de la APU. Al inicio mantuvo, al igual que el resto, una fuerte proximidad con el pensamiento de Klein, pero luego se volcó al estudio sistemático de la obra de Lacan. En este fragmento, el autor está comentando un caso clínico que publicó en 1952 (en su época kleiniana), por lo que la aclaración también podría funcionar como una rectificación

${ }^{12}$ Entre la variedad de formas de fijación de un sentido que describe AuthierRevuz (1992/1998), aquí nos encontraríamos ante lo que llama glosas solo en la forma negativa, cuya estructura formal sería: "X, no en el sentido de q" (p. 32). Estas formas de fijación de un sentido atestiguan una "no-unicidad" potencial del sentido de algún elemento del discurso; la operación se opone a esta "no-unicidad" fijando un único sentido a través de la eliminación de otro sentido inoportuno, impertinente, que sin embargo el elemento en cuestión autoriza o favorece (Authier-Revuz, 1992/1998, p. 31). El "pecho", en el contexto discursivo en el que está - un caso clínico en una época en que las ideas kleinianas tenían un lugar dominante - induce, autoriza, favorece, un sentido kleiniano: "que el concepto de 'pecho' sea un concepto central en la metapsicología kleiniana, creo que no suscita ninguna duda para ninguno de nosotros. (...) El pecho es (...) el punto de llegada o el punto final de la interpretación psicoanalítica" (W. Baranger, 1976/1984, pp. 15-16). 
de su lectura de aquel momento. En cualquier caso, sea para advertir a un posible lector desprevenido o para rectificar su antigua posición, se trata de un mismo fenómeno: a través de su explicitación, de su aclaración, el autor testimonia la potencialidad de "otro sentido" (kleiniano), que él encuentra y del cual "debe proteger activamente su decir" (Authier-Revuz, 1992/1998, p. 31). Si hay un sentido del cual protegerse y del cual proteger al lector, es porque se esboza una "lucha" entre formaciones discursivas, una lucha por el sentido de las palabras. Véase cómo se representa una frontera del discurso, con un aparente interior y exterior; discurso que se define a sí mismo, en este punto, por ser "no-kleiniano". Esta denegación testimonia, al mismo tiempo, la "omnipresencia" del sentido kleiniano en aquella época. Como plantea Authier-Revuz (1984/1990, p. 33), la omnipresencia del Otro se manifiesta precisamente en los lugares en que se intenta negar. A continuación presentamos fragmentos que suponen una operación similar:

(5) La sustancia del inconsciente no son residuos instintivos ni imágenes parentales sino la materia de la letra. (Koolhaas, 1972, p. 359)

(6) [Lo inconsciente] No debe ser confundido con lo no consciente. No es lo instintivo. No es lo arcaico. No es lo primordial. No es el lugar de las divinidades de la noche. Es el discurso del Otro. (Sopena, 1976, pp. 225-226)

(7) Lo inconsciente no es significado latente sino significantes en cadena que en otro lugar - en otra escena, decía Freud - se repiten e insisten para interferir en el discurso y el pensamiento conscientes. (Sopena, 1976, p. 226)

También existen otros casos en los que la operación de denegación no se da en torno a un sentido puramente teórico, sino en relación a una forma de proceder en la práctica clínica:

(8) No interpreto la relación conmigo porque mi preocupación se orienta a escuchar el discurso familiar, considerando el síntoma como un lenguaje por descifrar, y a procurar poner palabras a lo no dicho, al silencio. (Mieres de Pizzolanti, 1976, p. 354)

(9) El anuncio del embarazo lo sentí como un serio ataque a la marcha del tratamiento; sin embargo no se analizó la situación dual transferencial... (Mieres de Pizzolanti, 1976, p. 359)

En (8) se observa una forma de denegación: "no interpreto la relación conmigo". Con esta aclaración, que parece imponerse como necesaria ¿por qué decir lo que no hizo y no limitarse a decir, simplemente, lo que hizo? - , se establece una distancia respecto de la forma usual de intervenir en el psicoanálisis kleiniano tal como se practicaba en el Río de la Plata: la 


\section{HISTÓRIA DA PSICANÁLISE}

interpretación de la transferencia "aquí, ahora, conmigo". A diferencia de los ejemplos anteriores, este distanciamiento del kleinismo se realiza a partir de la introducción de un elemento diferencial de la práctica clínica. Nuevamente, en (9) se hace énfasis en que "no se analizó la situación dual transferencial". Se puede leer este enunciado, al igual que en (8), como un rechazo, o un alejamiento "monitoreado", de la forma tradicional de intervención: desde el enfoque tradicional kleiniano, la analista hubiera analizado-interpretado la situación dual transferencial. ${ }^{13}$ No solo no interpreta la transferencia, sino que, como en (8), aclara que no lo hizo. Pero nótese que, aun así, no pudo dejar de leer el material de la forma "tradicional": continúa prestando atención a los sentimientos contratransferenciales del analista; lee-siente el anuncio de su paciente como si estuviera dirigido al tratamiento y a su propia persona ("lo sentí como un serio ataque").

\section{Diferenciación por disyunción exclusiva}

Ubicamos aquí otra forma de diferenciación, que se caracteriza por oponer kleinismo y lacanismo como teorías o versiones recíprocamente excluyentes: una o la otra, pero no las dos. Aparecen puntos de bifurcación en los cuales los analistas son empujados a una elección, disyuntiva exclusiva, entre una $\mathrm{u}$ otra perspectiva. Las fronteras discursivas son representadas, de cierta forma, como "infranqueables". Véase el siguiente material discursivo:

(10) Me interesa destacar dos aspectos de este texto. Primero que Freud reitera la dificultad - o imposibilidad, según los casos — para el niño de aceptar que su madre carece de pene y la vincula con el culto a deidades femeninas mitológicas, en las que la adición de un falo al cuerpo femenino buscaba

${ }^{13}$ Estos procesos de diferenciación Klein-Lacan, a partir de los cuales se subrayan las diferencias en la práctica clínica, no se dieron únicamente en el ámbito de la APU. A modo de ejemplo, transcribimos parte de un texto publicado por una de las fundadoras de la EFM, en el que se hace referencia a un caso clínico: "en otro momento de mi práctica me hubiese apresurado a interpretarle, guiándome por el contexto de las asociaciones anteriores, algo así como que él se sentía frustrado por este ajuste de honorarios, humillado porque piensa que una mujer le está sacando eso valioso que es para él el dinero y que por eso desvaloriza lo que hacemos que se vuelve para él un comercio sucio, clandestino. No niego que estos elementos estén en juego en la transferencia, pero preferí seguir escuchando hacia dónde se deslizaba esta situación" (Capurro, 1982, pp. 31-32). 
definir la fuerza creadora primaria, que, uniendo en uno a ambos sexos, lograría representar la perfección. Es ésta la versión de la madre fálica deseada como tal (no temida), que retomarán los lacanianos. El segundo aspecto que deseo subrayar es que Freud también provee a los kleinianos de un punto de partida para la otra versión de la madre fálica (pareja combinada); y es cuando, en una nota agregada en 1919, presenta un dibujo de Leonardo en el que aparece esbozada una pareja en coito y el interior del cuerpo de la mujer está representado en forma por demás confusa (con comunicación entre pechos y genitales y contenidos extraños e indefinibles)... (de Urtubey, 1972, pp. 387-388)

Se hace referencia a "los lacanianos" y a "los kleinianos" en función de sus diferentes lecturas-versiones de la "madre fálica" que se desprenden del texto de Freud. "Es ésta la versión de la madre fálica deseada como tal (no temida), que retomarán los lacanianos". Obsérvese la acotación entre paréntesis, ¿qué función cumple? Enfatiza la diferencia, incluso la oposición, respecto al kleinismo. Según la perspectiva de Klein, la "madre fálica" es fuente de temor, de ansiedades: "mediante el análisis de niños he aprendido que el terror a la mujer con pene (...) es en realidad temor a la madre en cuyo cuerpo se asume que está el pene paterno" (Klein, 1928/2011, p. 322). Así, las dos lecturas-versiones de Freud se excluirían recíprocamente: o la madre fálica es deseada, o es temida. Una operación similar ocurre en el siguiente fragmento:

(11) De lo antedicho parece desprenderse que la zapatilla representa al pene de la madre. Pero, ¿cuál? ¿El que en el sentido freudiano debiera poseer para que él estuviera protegido de la angustia de castración? ¿O el pene perseguidor unido a la analista-madre, pegado a su cuerpo en una unión sorprendente y terrible, a la que desearía atacar con orina? (...). Creo que se trata del objeto parcial pene perseguidor, en un nivel oral y genital, unido a la madre. (...). En sesiones siguientes aparecen varios sueños sobre pozos enormes y sucios y temor de ser tragado por remolinos. Éstos podrían ser objeto de dos líneas interpretativas. Una freudiana según la cual teme que yo no tenga pene, esté castrada, el pozo sea la herida que dejó mi castración y esto anticipe el peligro de su propia castración por parte del padre edípico. El pozo también, en sentido lacaniano, representaría "lo que me falta". Otro sueño contemporáneo podría verse como confirmando estas interpretaciones: veía a la madre desnuda, con pene. Pero también una línea interpretativa kleiniana incluiría que mi interior es horrendo, no por castrado sino por lo sucio — anal — y tragador — oral que contiene. En estos momentos, desearía "taparlo" con un pene "fantasma", con el mismo sentido que se ha observado que tiene esa fantasía en la mujer. (...). Yo seguí esta línea interpretativa, a la que respondió con nuevos sueños. 


\section{HISTÓRIA DA PSICANÁLISE}

Un sábado soñó que tenía hora de análisis y venía, pero al llegar al consultorio encontraba dentro a uno de sus profesores, transformado en mecánico, que manejaba unos grandes instrumentos cortantes o como pinzas. Él luchaba contra este personaje y lograba expulsarlo. Se despertó en ese momento, fue al baño, prendió la luz y se masturbó introduciendo el pene en una zapatilla y colocando a la otra enfrente, "mirando". Me parece claro que se trata de una fantasía de presencia del pene perseguidor en mi interior y lucha edípica para extraerlo. (de Urtubey, 1972, pp. 413-415)

Aquí parece presentársele a la analista una encrucijada interpretativa; debe decidir si leer el material de forma "freudiana" o de forma "kleiniana": "pero, ¿cuál? ¿El que en el sentido freudiano debiera poseer para que él estuviera protegido de la angustia de castración? ¿O [en el "sentido kleiniano"] el pene perseguidor unido a la analista-madre, pegado a su cuerpo en una unión sorprendente y terrible, a la que desearía atacar con orina?". Esta encrucijada se presenta como una bifurcación interpretativa, como una disyuntiva: una u otra, pero no las dos. Finalmente, opta por la vía "kleiniana" de interpretación ("creo que se trata de objeto parcial pene perseguidor").

A continuación se presenta, nuevamente, una bifurcación similar: "estos podrían ser objeto de dos líneas interpretativas. Una freudiana según la cual teme que yo no tenga pene, esté castrada, el pozo sea la herida que dejó mi castración y esto anticipe el peligro de su propia castración por parte del padre edípico. El pozo también, en sentido lacaniano, representaría 'lo que me falta'. (...). Pero también una línea interpretativa kleiniana incluiría que mi interior es horrendo, no por castrado sino por lo sucio - anal - y tragador - oral - que contiene". Tendríamos una vía "freudiana" y junto con ella una posible vía "lacaniana"; así, la vía "freudiana" queda asociada con la vía "lacaniana", y ambas se opondrían a la vía "kleiniana". Ante esta segunda bifurcación interpretativa — Freud-Lacan o Klein — sigue, otra vez, la línea "kleiniana", que luego habría sido confirmada como "correcta" con el material de sesiones siguientes. Estos fenómenos de disyunción se materializan aquí por la vía de la conjunción disyuntiva "o" en un sentido exclusivo (en la primera bifurcación interpretativa) y de la conjunción adversativa "pero" (en la segunda).

Nótese que las diferencias son siempre en función del contenido, del significado de la interpretación - en sentido "freudiano" es la "herida que dejó mi castración", en sentido "lacaniano" el pozo "representaría lo que me falta", y en sentido "kleiniano" "mi interior es horrendo (...) por lo sucio (...) y tragador (...) que contiene" —, y no de su lógica subyacente. Sin 
embargo, desde la lógica lacaniana ninguna interpretación podría sostenerse en la estructura " $x$ representa/significa/simboliza $z$ ", puesto que la n oción de signi icante se distingue netamente de la noción de representación (cf. Grau- Pérez, 2018); ningún elemento signi icante vale por sí mismo y no existe relación intrínseca entre signi icante y signi icado. Por lo tanto, "el pozo", en "sentido lacaniano", nunca podría representar, en sí mismo, "lo que me falta". Lacan es leído aquí desde una lógica kleiniana, es decir, por vía del signi icado, al que se llega por analogía: como a los pozos les falta algo, podrían representar "la falta". Por lo tanto, en este caso, la forma por la cual se establece la diferenciación - si bien se representa una diferencia incompatible, una disyunción exclusiva disimula-opaci ica una determinación kleiniana.

\section{Consideraciones finales}

Hemos descrito, a partir de las producciones textuales de algunos analistas de aquella época — décadas de 1960 y 1970 — diferentes procesos de hibridación discursiva entre kleinismo y lacanismo. Estos procesos de hibridación producirían un efecto de disimulación de la inconmensurabilidad entre ambos paradigmas, y al mismo tiempo, opacificarían la relación de subordinación entre ellos: a grandes rasgos, las ideas lacanianas habrían sido leídas - al menos en un momento - desde las coordenadas del kleinismo, como si hubieran sido "asimiladas", "metabolizadas", "transformadas", en función del paradigma previo. ${ }^{14}$ En este sentido, se podría considerar la hibridación como una forma de "negociación", o de "solución de compromiso", entre paradigmas; aunque, dada la relación de subordinación, se trataría de un compromiso desigual.

En este punto conviene resistir la tentación de reducir toda hibridación a una simple "impericia” o "ingenuidad”. Según Bajtín (1975/1989, p. 175), la lengua y los lenguajes se modifican a través de la hibridación. De forma análoga, podríamos decir que la teoría se transforma, en muchos casos, a

${ }^{14}$ Según Bernardi (2003): "la situación de inconmensurabilidad puede estar disimulada detrás de una aparente integración o pseudo-integración de teorías. Esto ocurre cuando se utilizan teorías psicoanalíticas muy diferentes entre sí sin que exista ningún tipo de cotejo entre ellas y sin prestar atención a la coherencia interna del razonamiento" (p. 127). 
partir de procesos de hibridación; transportar elementos de una teoría hacia otra podría producir sentidos novedosos, impensados, como efecto de una operación de resignificación (cf. Milán-Ramos, 2019). Se trataría de un efecto metafórico, a partir del cual los elementos de una secuencia textual, funcionando en una determinada formación discursiva, son importados por una secuencia perteneciente a otra formación discursiva (Pêcheux, 1984/2015a, p. 158). Igualmente, este efecto podría ser concebido como un fenómeno de frontera, en el cual la inscripción a una u otra formación discursiva se torna indecidible (cf. Pêcheux, 1983/1997, p. 314). Fenómenos de hibridación como los que repasamos aquí permitirían comprender mejor el alcance de la afirmación de Pêcheux (1978/2014, p. 280) de que el pensamiento teórico es fundamentalmente inconsciente. Asimismo, tal vez se podría considerar que habría hibridaciones "logradas", con producción de nuevas regiones discursivas, nuevos objetos, nuevos sentidos, e hibridaciones "fallidas" o "estériles", que no conllevarían este aspecto productivo.

Estos diferentes entrecruzamientos e hibridaciones hacen vacilar la unidad y estabilidad de las formaciones discursivas que establecimos como punto de partida, aunque sin por ello disolverlas. La noción de formación discursiva admite - a diferencia de la noción de paradigma de Kuhn — la heterogeneidad constitutiva, la tensión paradojal entre unidad y dispersión. ${ }^{15}$ Pêcheux (1984/2015a, pp. 156-157) argumenta que la noción foucaultiana de formación discursiva permitiría operar con una concepción de discursividad en la cual los efectos del interdiscurso no quedarían resueltos en un punto de integración, sino que se desarrollarían en sucesivas y diversas contradicciones.

Por otra parte, hemos descrito distintos procesos de diferenciación discursiva, que mostrarían que el lacanismo se constituyó en Uruguay, en un primer momento, en oposición al kleinismo. A partir de estas operaciones de diferenciación respecto del kleinismo se fue representando la frontera a través de la cual el lacanismo se delimitó a sí mismo y adquirió relativa autonomía. ¿Habría ocurrido un fenómeno similar en otros países de América Latina, como Argentina, Brasil o Chile, donde también existió cierta "hegemonía" kleiniana? Como dice Marie-Claude Thomas (2008): “¿quién de los analistas

${ }^{15}$ El paradigma constituiría lo que Pêcheux (1983/2015b) describió como un "espacio de predicados, de argumentos y relaciones lógicamente estabilizado" (p. 23), mientras que una formación discursiva podría operar también a partir de "una serie heterogénea de enunciados, funcionando sobre diferentes registros discursivos, y con una estabilidad lógica variable" (Pêcheux, 1983/2015b, p. 23). 
lacanianos de América Latina, primero kleinianos, no se siente avergonzado por ello?" (p. 40). Esta "vergüenza", ¿sería una marca del propio proceso de constitución del lacanismo en América Latina? Asimismo, podríamos preguntarnos si esto no supondría una diferencia relevante con el lacanismo de otras partes del mundo, cuya constitución habría estado mediada por otras teorías, otros discursos.

No es posible describir y comprender la constitución del lacanismo en Uruguay sin tener en cuenta el kleinismo, y en particular, los procesos discursivos por los cuales se fue balizando el terreno: los puntos específicos que establecieron diferencias, los lugares elegidos que constituyeron fronteras y demarcaciones. Apoyado en los trabajos de Foucault, Dunker (2011) plantea que "toda práctica puede ser pensada en discontinuidad con prácticas que la precedieron y la tornaron posible" (p. 45). En este sentido, señala que algo debe ser perdido, a modo de corte radical, para que una práctica adquiera autonomía, visibilidad y legitimidad. Habría un esfuerzo de diferenciación con algo anterior, un esfuerzo por hacer visible una discontinuidad. Las formas de diferenciación que hemos presentado proceden muchas veces de esta manera, marcando diferencias en determinados puntos de la teoría y de la práctica clínica. Aunque en ocasiones, las diferencias quedaban representadas en función de contenidos muy específicos, y no tanto en un sentido global y en relación a la lógica divergente que subyace a ambos paradigmas. Eventualmente, se perdía de vista que la teoría lacaniana implicaba una resignificación o transformación masiva de los operadores conceptuales clásicos del psicoanálisis; se representaban diferencias, pero al mismo tiempo podían quedar invisibilizados los puntos en donde la inconmensurabilidad se planteaba de forma más fundamental. De esta manera, la diferenciación también funcionaba, en algunos casos, como una forma de disimulación de la inconmensurabilidad.

El eje de nuestra investigación ha estado en los procesos y fenómenos discursivos que marcaron la relación entre kleinismo y lacanismo en el contexto de la recepción de Lacan producida en la APU; no hemos centrado nuestra atención en el ruta de recepción que se dio en torno al Grupo Freudiano de Trabajo, y que culminó con la fundación de la EFM. Para avanzar en la localización de estos procesos, sería imprescindible abordar - en una futura investigación - este otro plano, puesto que la EFM se constituye, en la década de 1980, como el polo principal de implantación, formación, y difusión del lacanismo en Uruguay. De allí surgirán luego las 


\section{HISTÓRIA DA PSICANÁLISE}

diferentes escisiones a partir de las cuales se formarán los diversos grupos, escuelas y redes lacanianas que existen en la actualidad en Montevideo.

\section{Referencias}

Allouch, J. (1994). El punto de vista lacaniano en psicoanálisis. Litoral, 16, 81-101. Allouch, J. (2006). Freud, y después Lacan. Mexico, D.F.: Epeele. (Trabajo original publicado en 1993).

Authier-Revuz, J. (1990). Heterogeneidade(s) enunciativas(s). Cadernos de Estudos Lingüísticos, 19, 25-42. (Trabajo original publicado en 1984).

Authier-Revuz, J. (1998). Palavras incertas. As não coincidências do dizer. Campinas, SP: Editora da Unicamp. (Trabajo original publicado en 1992).

Bajtín, M. (1989). Teoría y estética de la novela. Trabajos de investigación. Madrid, España: Taurus. (Trabajo original publicado en 1975).

Balán, J. (1991). Cuéntame tu vida. Una biografía colectiva del psicoanalisis argentino. Buenos Aires, Argentina: Editorial Planeta Argentina.

Baños Orellana, J. (1995). El idioma de los lacanianos. Buenos Aires, Argentina: Atuel.

Baranger, M., \& Baranger, W. (1964). El "insight" en la situación analítica. Revista Uruguaya de Psicoanálisis, 6(1), 19-38.

Baranger, W. (1984). Conferencia de Willi Baranger "No olvidar a Melanie Klein". Temas de Psicoanálisis, 4, 15-22. (Trabajo original publicado en 1976).

Bernardi, R. (1989). The Role of Paradigmatic Determinants in Psychoanalytic Understanding. The International Journal of Psychoanalysis, 70, 341-357.

Bernardi, R. (2002). Por qué Klein y por qué no Klein. Reflexiones sobre el desarrollo de las ideas psicoanalíticas en el Río de la Plata. Revista de Psicoanálisis, 59, 263-273.

Bernardi, R. (2003). La necesidad de verdaderas controversias en psicoanálisis. Los debates sobre M. Klein y J. Lacan en el Río de la Plata. Revista Uruguaya de Psicoanálisis, 97, 113-158.

Bernardi, R. (2010). Nota sobre la obra de G. Koolhaas. A propósito de la recepción de las ideas de Lacan en el Río de la Plata. Revista Uruguaya de Psicoanálisis, $111,87-102$.

Birman, J. (2014). Os paradigmas em psicanálise. In J. Birman, D. Kupermann, E. Leal Cunha, \& L. Fulgencio (Eds.), A fabricação do humano. Psicanálise, Subjetivação e Cultura (pp. 17-42). São Paulo, SP: Zagodoni. 
Capurro, R. (1982). Concepciones de la cura. Cuaderno de Psicoanálisis Freudiano, $3,23-34$.

Dagfal, A. (2009). Entre París y Buenos Aires. La invención del psicólogo (1942-1966). Buenos Aires, Argentina: Paidós.

De Urtubey, L. (1972). El fetichismo como "solución” al edipo temprano. Revista Uruguaya de Psicoanálisis, 13(4), 385-432.

Dunker, C. (2011). Estrutura e constituição da clínica psicanalítica. Uma arqueologia das práticas de cura, psicoterapia e tratamento. São Paulo, SP: Annablume.

Dunker, C., Paulon, C., \& Milán-Ramos, J. G. (2016). Análise Psicanalítica de Discurso. Perspectivas Lacanianas. São Paulo, SP: Estação das Letras e Cores.

Foucault, M. (2000). Los anormales. Buenos Aires, Argentina: Fondo de Cultura Económica de Argentina. (Trabajo original publicado en 1975).

Foucault, M. (2002). La arqueología del saber. Buenos Aires, Argentina: Siglo Veintiuno.

Freud, S. (1976). La negación. In Obras completas. Tomo XIX. Buenos Aires, Argentina: Amorrortu. (Trabajo original publicado en 1925).

García Canclini, N. (1990). Culturas híbridas. Estrategias para entrar y salir de la modernidad. Mexico, D.F.: Editorial Grijalbo.

García, G. (2005). La entrada del psicoanálisis en la Argentina. In La entrada del psicoanálisis en la Argentina; La cronologia: nudos y redes. Buenos Aires, Argentina: Catálogos.

Grau Pérez, G. (2018). Klein con Lacan: un estudio discursivo de la recepción de las ideas lacanianas en Uruguay (1955-1982). Universidad de la República.

Izaguirre, M. (2009). Jacques Lacan: El anclaje de su enseñanza en la Argentina. Buenos Aires, Argentina: Catálogos.

Klein, M. (2011). Nota sobre "Un sueño de interés forense" (CONTRIBUCIONES BREVES). In Obras completas de Melanie Klein. 3 - Envidia y gratitud y otros trabajos. Buenos Aires, Argentina: Paidós. (Trabajo original publicado en 1928).

Koolhaas, G. (1972). ¿Quién es el Otro? Revista Uruguaya de Psicoanálisis, 13(4), 349-383.

Lacan, J. (2002). Función y campo de la palabra y del lenguaje en psicoanálisis. In Escritos 1. Buenos Aires, Argentina: Siglo Veintiuno. (Trabajo original publicado en 1956).

Mieres de Pizzolanti, G. (1976). Del silencio y la opresión al deseo y la palabra. Revista Uruguaya de Psicoanálisis, 14(3), 353-370. 


\section{HISTÓRIA DA PSICANÁLISE}

Milán-Ramos, J. G. (2019). Pêcheux, Frege, Lacan, a meio caminho entre teoria e objeto. In N. Lara Junior, C. Lenz Dunker, \& D. Pavón-Cuéllar (Orgs.), Análise lacaniana de discurso. Subversão e pesquisa crítica. Curitiba, PR: Appris.

Pêcheux, M. (1997). A análise de discurso: três épocas. In F. Gadet, \& T. Hak (Eds.), Por uma análise automática do discurso: uma introdução à obra de Michel Pêcheux (pp. 311-318). Campinas, SP: Editora da Unicamp. (Trabajo original publicado en 1983).

Pêcheux, M. (2014). Só há causa daquilo que falha ou o inverno político francês: início de uma retificação. In Semântica e discurso. Uma crítica à afirmação do óbvio (pp. 269-281). Campinas, SP: Editora da Unicamp. (Trabajo original publicado en 1978).

Pêcheux, M. (2015a). Metáfora e Interdiscurso. In E. Puccinelli Orlandi (Ed.), Análise de discurso. Michel Pêcheux (pp. 151-161). Campinas, SP: Pontes. (Trabajo original publicado en 1984).

Pêcheux, M. (2015b). O discurso. Estrutura ou acontecimento. Campinas, SP: Pontes. (Trabajo original publicado en 1983).

Pêcheux, M. (2016). Las verdades evidentes. Lingüística, semántica, filosofía. Buenos Aires, Argentina: Ediciones del CCC Centro Cultural de la Cooperación Floreal Gorini. (Trabajo original publicado en 1975).

Plá, J. C. (1970). El periodo de comunicación oniroide en el análisis de Griselda: a la búsqueda de un sujeto por el camino del teatro y del sueño. Revista Uruguaya de Psicoanálisis, 12(4), 359-401.

Plotkin, M. (2003). Freud en las Pampas. Orígenes y desarrollo de una cultura psicoanalítica en la Argentina (1910-1983). Buenos Aires, Argentina: Editorial Sudamericana.

Real Academia Española, \& Asociación de Academias de la Lengua Española. (2009). Nueva gramática de la lengua española. Sintaxis II. Madrid, España: Espasa Libros.

Segal, H. (1981). Introducción a la obra de Melanie Klein. Barcelona, España: Paidós. (Trabalho original publicado em 1964).

Sopena, C. (1969). Acerca del hablar y el interpretar. Revista Uruguaya de Psicoanálisis, 11(1), 5-28.

Sopena, C. (1976). Notas sobre la noción de inconsciente en Lacan. Revista Uruguaya de Psicoanálisis, 14(2), 225-233.

Thomas, M.-C. (2008). Lacan lector de Melanie Klein. Consecuencias para el "psicoanálisis de niños." Mexico, D.F.: EPEELE. 


\section{Resumenes}

(Hibridização e diferenciação discursiva entre kleinismo e lacanismo (Uruguai,1955-1982)

As ideias lacanianas chegam ao Uruguai na década de 1960, em um contexto de hegemonia kleiniana. Neste trabalho, descrevemos os processos e os fenômenos discursivos a partir dos quais o lacanismo se relaciona e se articula com o kleinismo da época.

Para realizar esta pesquisa, construiu-se um corpus de dados discursivos a partir de casos clínicos e artigos teórico-doutrinários publicados na Revista Uruguaya de Psicoanálisis entre 1955 e 1982.

Os materiais discursivos que constituem o corpus apresentam diversos modos de entrecruzamento, hibridização e diferenciação entre teorias. A partir desses fenômenos, alguns aspectos do processo de recepção de Lacan no Uruguai são discutidos.

Palavras-chave: Kleinismo, lacanismo, Uruguai, análise do discurso

(Discursive hybridization and differentiation between Kleinism and Lacanism (Urugauy, 1955-1982)

In Uruguay, Lacanian ideas arrived in the 1960s, in a context of Kleinian hegemony. In this paper, discursive processes and phenomena based on which Lacanism relates and articulates with Kleinism of the time are described.

To carry out this research, a corpus of discursive data was constructed based on clinical cases and theoretical-doctrinal papers published in the "Revista Uruguaya de Psicoanálisis" between 1955 and 1982.

The discursive materials that constitute the corpus display several modes of cross-linking, hybridization and differentiation between theories. Based on these phenomena, some aspects of the Lacan reception process in Uruguay are discussed.

Key words: Kleinism, Lacanism, Uruguay, discourse analysis

(Hybridation et différenciation discursive entre kleinisme et lacanism (Uruguay, 1955-1982)

En Uruguay, les idées lacaniennes surgissent dans les années 1960, dans un contexte d'hégémonie kleinienne. Dans cette étude, nous décrivons les processus discursifs à partir desquels le lacanisme se rapporte et s'articule avec le kleinisme de l'époque.

Pour mener à bien cette recherche, un relevé de données discursives a été construit à partir de cas cliniques et d'articles théoriques et doctrinaux publiés dans la « Revista Uruguaya de Psicoanálisis » entre 1955 et 1982.

Les matériels discursifs constituant l'ensemble des données présentent divers modes d'entrecroisement, d'hybridation et de différenciation entre les théories. À 


\section{HISTÓRIA DA PSICANÁLISE}

partir de ces phénomènes, certains aspects du processus de réception Lacan en Uruguay sont objet de discussion.

Mots clés: Kleinisme, Lacanisme, Uruguay, analyse du discours

(Hybridisierung und diskursive Differenzierung zwischen Kleinismus und Lacanismus (Uruguay, 1955-1982)

Lacans Ideen treffen in den 1960er Jahren in Uruguay auf einen Kontext in dem Kleins Ideen vorherrschen. Dieser Artikel beschreibt die diskursiven Prozesse und Phänomene, die zu einer Beziehung und zu einem Zusammenhang zwischen dem Lacanismus und dem Kleinismus in dieser Zeit führen.

Dazu erstellten wir einen Korpus diskursiver Daten von klinischen Fällen und theoretisch-doktrinären Artikeln, die von 1955 bis 1982 in der Revista Uruguaya de Psicoanálisis veröffentlicht wurden.

Das diskursive Material, aus dem sich unser Korpus zusammensetzt, zeigt die unterschiedlichen Arten der Kreuzung, Hybridisierung und Differenzierung zwischen diesen beiden Theorien auf. Aufgrund dieser Phänomene wird beschrieben, wie Lacans Lehre damals in Uruguay aufgenommen wurde.

Schlüsselwörter: Kleinismus, Lacanismus, Uruguay, Diskursanalyse

Citação/Citation: Grau-Pérez, G., \& Milán, G. (2019, dez.). Hibridación y diferenciación discursiva entre kleinismo y lacanismo (Uruguay,1955-1982). Revista Latinoamericana de Psicopatologia Fundamental, 22(4), 884-908. htttp:// dx.doi.org/10.1590/1415-4714.2019v-22n4p884-12.

Editora/Editor: Profa. Dra. Ana Maria Rudge

Submetido/Submitted: 29.3.2019/3.29.2019 Aceito/Accepted: 5.5.2019/ 5.5.2019

Copyright: (C) 2009 Associação Universitária de Pesquisa em Psicopatologia Fundamental/ University Association for Research in Fundamental Psychopathology. Este é um artigo de livre acesso, que permite uso irrestrito, distribuição e reprodução em qualquer meio, desde que $\mathrm{o}$ autor e a fonte sejam citados / This is an open-access article, which permits unrestricted use, distribution, and reproduction in any medium, provided the original authors and sources are credited. 
Financiamento/Funding: Este trabalho recebeu apoio da Agencia Nacional de Investigación e Innovación (ANII) / This work was funded by Agencia Nacional de Investigación e Innovación (ANII).

Conflito de interesses/Conflict of interest: Os autores declaram que não há conflito de interesses / The authors declare that there is no conflict of interest.

\section{Gonzalo Grau PÉrez}

Licenciado en Psicología y Magíster en Psicologia Clínica. Docente de la Universidad de la República (Montevideo, Uruguay).

Tristán Narvaja, 1674

Montevideo, Uruguay

gongrau@gmail.com

https://orcid.org/0000-0002-5280-3572

\section{Guillermo Milán}

Licenciado y Doctor en Lingüística. Docente de la Universidad de la República (Montevideo, Uruguay).

Tristán Narvaja, 1674

Montevideo, Uruguay

guillermo.milan@yahoo.com

https://orcid.org/0000-0002-0531-096X

\section{ERRATA}

No artigo "Hibridación y diferenciación discursiva entre kleinismo y lacanismo (Uruguay,1955-1982)" dos autores Gonzalo Grau Pérez, Guillermo Milán, com número de DOI 10.1590/1415-4714.2019v22n4p884-12, publicado na Revista Latinoamericana de Psicopatologia Fundamental, volume 22, número 4 (Rev. Latinoam.Psicopatol.Fundam. 22(4), 884-908, nas páginas 884 e 908

Onde se lia:

Gonzalo Grau Pérez*2

Gonzalo Grau Pérez

Leia-se

Gonzalo Grau-Pérez*2

Gonzalo Grau-Pérez

\section{(cc) BY-NC}

This is an open-access article, which permits unrestricted use, distribution, and reproduction in any medium for non-commercial purposes provided the original authors and sources are credited. 